\title{
A BUSCA PELA CONCORDÂNCIA PRÁTICA E OS LIMITES AO "MÉTODO DA PONDERAÇÃO DE BENS CONSTITUCIONAIS"
}

DANIEL GAIO ${ }^{1}$

\begin{abstract}
RESUMO: Um dos problemas centrais na interpretação e aplicação do direito consiste na escolha da metodologia para a resolução dos conflitos. O texto objetiva demonstrar que a busca pela concordância prática propicia maior efetividade ao conjunto dos valores constitucionais; ao contrário do que ocorre com o método da ponderação de bens no caso concreto, que reduz a tarefa de harmonização ao princípio da proporcionalidade.

PALAVRAS-CHAVE: Harmonização; Concordância; Ponderação; Constituição; Conflitos.

ABSTRACT: One of the central problems in the interpretation and application of law is the choice of methodology for the resolution of conflicts. The text aims to demonstrate that the search for practical agreement provides greater effectiveness to the set of constitutional values - contrary to what occurs with the balancing method of goods in the concrete case, which reduces the task of harmonization to the principle of proportionality.

KEYWORDS: Harmonization; Agreement, Balance; Constitution; Conflicts.
\end{abstract}

SUMÁRIO: Introdução; 1 A Ordem Constitucional de Valores e a Aplicação Subsidiária do "Método da Ponderação de Bens"; 2 Advertências Metodológicas Finais; Referências Bibliográficas.

SUMMARY: Introduction; 1 The Constitucional System of Values and the Subsidiary Application of the "Balancing Method of Constitucional Goods"; 2 Final Methodological Warning; Bibliographical References.

\section{INTRODUÇÃO}

A existência de antinomias é frequente em qualquer ramo do direito; e não poderia ser diferente em sistemas constitucionais que possuem um

Artigo recebido em 16.06.2011. Pareceres emitidos em 22.07.2011, 26.08.2011 e 05.01.2012. Artigo aceito para publicação em 12.03.2012.

${ }^{1}$ Doutor em Direito pela Pontifícia Universidade Católica do Rio de Janeiro, com estágio de doutoramento na Università di Bologna. Mestre em Ciências Jurídico-Políticas pela Universidade de Lisboa. Professor Adjunto I nos cursos de graduação e mestrado em Direito da Universidade Federal do Amapá - UNIFAP. Líder do Grupo de Pesquisa "Direito e Meio Ambiente nas Cidades", do CNPq. Membro da Associação dos Professores de Direito Ambiental do Brasil - APRODAB e do Instituto Brasileiro de Direito Urbanístico - IBDU. danielgaio72@yahoo.com.br 
amplo rol de direitos fundamentais, muitos dos quais positivados com base em ideologias e interesses bastante heterogêneos ${ }^{2}$. Esse é o caso específico da Constituição brasileira de 1988, pois, ao mesmo tempo em que possui forte cunho programático e dirigente, prevê dispositivos que mitigam e limitam a efetividade do conjunto de direitos ${ }^{3}$, como sucedeu na deliberada estratégia em condicionar a aplicação de instrumentos garantidores da função social da propriedade realizada pelos municípios à edição de lei federal regulamentadora ${ }^{4}$.

Além disso, embora não seja possível desconsiderar as influências de textos constitucionais estrangeiros ${ }^{5}$ e de seus mais renomados intérpretes ${ }^{6}$, a Constituição de 1988 foi promulgada sem que estivesse estruturada no Brasil uma teoria dos direitos fundamentais, o que gerou um déficit de interpretação e concretização nessa área ${ }^{7}$.

Após um lento processo de afirmação e supremacia dos valores constitucionais em face do ordenamento infraconstitucional anterior - no qual o exemplo mais paradigmático dessa dificuldade consistiu na resistência em atribuir à codificação civil com matriz oitocentista o papel de centro das relações privadas ${ }^{8}$-, atualmente é amplamente defendido que os conflitos entre direitos fundamentais sejam resolvidos pelo método da ponderação de bens no caso concreto.

Entretanto, como o referido método se pauta pela lógica do "tudo ou nada", pois permite a nula realização prática, no caso concreto, de um valor oposto $^{9}$, ele somente deve ser aplicado se, diante das circunstâncias da

${ }^{2}$ Cf. PRIETO SANCHÍS, L. Justicia Constitucional y Derechos Fundamentales, p. 175-176.

${ }^{3}$ Um panorama geral acerca das características da Constituição brasileira de 1988 pode ser encontrado em SARLET, I. W. A Eficácia dos Direitos Fundamentais, p. 73-80.

${ }^{4} \mathrm{Cf} . \mathrm{o}$ art. $182, \S 4^{\circ}, \mathrm{CF}$.

${ }^{5}$ Citam-se, em especial, as Constituições de Portugal (1976) e da Espanha (1978), ambas promulgadas após longo período de regime autoritário, de maneira similar ao caso brasileiro.

${ }^{6}$ Por todos, ver a obra de Gomes Canotilho publicada em 1982. Cf. CANOTILHO, J. J. G. Constituição Dirigente e Vinculação do Legislador. Assinala-se que o interesse e a relevância da referida obra subsistem na doutrina brasileira mesmo após a publicação de sua segunda edição em 2001. Cf. COUTINHO, J. N. M. Canotilho e a Constituição Dirigente.

${ }^{7}$ Como afirma Virgílio Afonso da Silva, o direito constitucional anterior a 1988 era muito mais estruturado em torno da organização estatal do que em relação aos direitos fundamentais. Cf. SILVA, V. A. Direitos Fundamentais - conteúdo essencial, restrições e eficácia, p. 66.

${ }^{8}$ Para os civilistas tradicionais, "os princípios constitucionais equivaleriam a normas políticas destinadas ao legislador e, apenas excepcionalmente, ao intérprete, que delas poderia timidamente se utilizar, nos termos do art. $4^{\circ}$ da Lei de Introdução ao Código Civil Brasileiro". Essa concepção acaba por relegar a norma constitucional a um elemento de integração subsidiário, aplicável apenas na ausência de norma ordinária específica e após terem sido frustradas as tentativas, pelo intérprete, de fazer uso de analogia e de regra consuetudinária. Cf. TEPEDINO, G. Normas Constitucionais e Relações de Direito Civil na Experiência Brasileira, p. 326. Veja-se que esse papel atribuído ao Código Civil foi dominante no século passado, até os anos 20 na Alemanha e até os anos 50 na Itália. Cf. GIANNINI, M. S. Basi Costituzionali della Proprietà Privata, p. 188-189.

${ }^{9}$ Cf. NOVAIS, J. R. As Restrições aos Direitos Fundamentais não Expressamente Autorizadas pela Constituição, p. 561.

DiREITOS FundAMENTAIS E JUSTIÇA - ANO 6, N' 18, P. 120-128, JAN./MAR. 2012 
situação, os valores constitucionais não puderem ser otimizados em todas as suas potencialidades ${ }^{10}$. Isso significa dizer que o método da ponderação de bens deve ser precedido por uma tentativa de harmonização entre os valores constitucionais - denominada "busca pela concordância prática" -, evitando-se a anulação integral da efetividade do direito fundamental.

\section{A ORDEM CONSTITUCIONAL DE VALORES E A APLICAÇÃO SUBSIDIÁRIA DO "MÉTODO DA PONDERAÇÃO DE BENS"}

Embora os próprios defensores do método da ponderação em concreto admitam a importância do processo de otimização dos direitos fundamentais, este praticamente se resume à realização do princípio da proporcionalidade em sentido amplo ${ }^{11}$. Além disso, ao privilegiar excessivamente as circunstâncias fáticas, o método da ponderação atribui pouca importância às soluções que foram antecipadas pelo legislador constituinte para a resolução dos conflitos.

Com efeito, ainda que necessário o recurso ao método da ponderação para os casos difíceis, notadamente quando o sistema constitucional não estabeleceu pesos diferenciados entre os bens, interesses e princípios constitucionais ${ }^{12}$, não há como ignorar a existência de uma ordem constitucional de valores ${ }^{13}$, tornando-se indispensável que essas escolhas realizadas pelo legislador constituinte sejam devidamente observadas quando existirem conflitos entre os valores constitucionais ${ }^{14}$.

Nesse sentido, assinala-se que o conteúdo de qualquer direito fundamental não pode ser determinado sem que se compreenda a sua relação com a totalidade do sistema jurídico-constitucional de valores. Tendo em vista que a integralidade dos valores constitucionais devem ser protegidos, portanto, dotados de efetividade, torna-se necessário que o âmbito de proteção de cada direito fundamental seja condicionado por uma reserva geral imanente ${ }^{15}$.

Esse entendimento, construído a partir de decisões da Corte Federal Constitucional alemã, tem como pressuposto que os direitos fundamentais não se limitam à sua dimensão subjetiva, mas que igualmente se vinculam a uma ordem objetiva de valores que incide sobre todo o ordenamento constitucional $\left.\right|^{16}$. Desse modo, ao impedir que um direito seja efetivado à

${ }^{10}$ Cf. CANOTILHO, J. J. G. Direito Constitucional e Teoria da Constituição, p. 1240; e HESSE, K. Temas Fundamentais do Direito Constitucional, p. 113.

${ }^{11}$ Cf. ALEXY, R. Teoria dos Direitos Fundamentais, p. 116-120; e LARENZ, K. Metodologia da Ciência do Direito, p. 586.

${ }_{12}$ Cf. PRIETO SANCHÍS, L. Justicia Constitucional y Derechos Fundamentales, p. 191; e GAVARA DE CARA, J. C. Derechos Fundamentales y Desarrollo Legislativo: La Garantia del Contenido Esencial de los Derechos Fundamentales en la Ley Fundamental de Bonn, p. 292.

${ }^{13}$ Cf. LARENZ, K. Metodologia da Ciência do Direito, p. 482-483.

${ }^{14} \mathrm{Cf}$. CANOTILHO, J. J. G. Direito Constitucional e Teoria da Constituição, p. 1240.

${ }^{15}$ Cf. ANDRADE, J. C. V. Os Direitos Fundamentais na Constituição Portuguesa de 1976 , p. 287; e NOVAIS, J. R. As Restrições aos Direitos Fundamentais não expressamente autorizadas pela Constituição, p. 570.

${ }^{16}$ Cf. SARLET, I. W. A Eficácia dos Direitos Fundamentais, p. 159. 
custa de outro, pretende-se que o conjunto dos valores constitucionais seja protegido $^{17}$. Isso significa dizer que todos os direitos fundamentais possuem uma função ético-jurídica e social, pois o seu conteúdo é definido em atenção a outros valores constitucionalmente reconhecidos, tornando-se resultado da inter-relação entre interesses públicos e individuais ${ }^{18}$.

Portanto, para que esse equilíbrio de interesses seja concretizado, deve-se reconhecer que há uma relação normativa-imanente entre os bens jurídico-constitucionais, além de considerar que todo valor constitucional é parte constitutiva de um conjunto, portanto, condicionado desde o princípio por outros valores igualmente relevantes ${ }^{19}$. Embora os limites imanentes não sejam constituídos apenas por cláusulas expressas ${ }^{20}$, note-se que a Constituição brasileira de 1988 estabeleceu de maneira direta um amplo catálogo de direitos fundamentais sociais, que condicionam e limitam de maneira intrínseca os direitos individuais.

Em suma, a determinação do conteúdo dos direitos fundamentais decorre de uma dimensão objetiva, a qual fundamenta explicitamente a correlação entre direitos e deveres ${ }^{21}$ a fim de que se garanta a satisfação, ao máximo possível, dos direitos individuais aos valores comunitários, como a saúde e o meio ambiente. Ademais, as limitações aos direitos fundamentais não servem apenas para exprimir uma relação de solidariedade, mas igualmente proporcionam a concretização dos direitos individuais, na medida em que o seu exercício depende de um número cada vez maior de prestações estatais $^{22}$.

Considerando que o alcance do âmbito de proteção de cada direito fundamental deve ser compatibilizado com os interesses individual, geral e de terceiros ${ }^{23}$, coloca-se em questão a árdua tarefa de identificar as diversas delimitações que incidem sobre o conteúdo do direito para, em seguida, definir as "realidades da vida" ${ }^{24}$ que são objeto de proteção constitucional.

Com efeito, além dos limites imanentes justificarem uma interpretação restritiva do direito fundamental ${ }^{25}$, é necessário verificar as ponderações abstratas específicas realizadas pelo legislador constituinte e que propiciam

${ }^{17}$ Cf. HÄBERLE, P. La Garantia del Contenido Esencial de los Derechos Fundamentales, p. 41.

${ }^{18}$ Cf. FERNANDEZ SEGADO, F. Estudio Preliminar. Peter Häberle: la giganteca construcción constitucional de um humanista europeo, p. LVII.

${ }^{19}$ Cf. HÄBERLE, P. La Garantia del Contenido Esencial de los Derechos Fundamentales, p. 62. Ver também LARENZ, K. Metodologia da Ciência do Direito, p. 483.

${ }^{20}$ Cf. HÄBERLE, P. La Garantia del Contenido Esencial de los Derechos Fundamentales, p. 10-11.

${ }^{21}$ Cf. ANDRADE, J. C. V. Os Direitos Fundamentais na Constituição Portuguesa de 1976, p. 168-170.

${ }_{22}$ Nesse sentido, ver o conceito de liberdade fática em ALEXY, R. Teoria dos Direitos Fundamentais, p. 503-511.

${ }^{23}$ Cf. MEDINA GUERRERO, M. La Vinculacion Negativa del Legislador a los Derechos Fundamentales, p. 13-15.

${ }^{24}$ Cf. CANOTILHO, J. J. G. Direito Constitucional e Teoria da Constituição, p. 1262. Note-se que a incorporação das circunstâncias da realidade que a norma é chamada a regular está sujeita a transformações históricas. Cf. HESSE, K. Temas Fundamentais do Direito Constitucional, p. 98-99.

${ }^{25}$ Cf. ANDRADE, J. C. V. Os Direitos Fundamentais na Constituição Portuguesa de 1976, p. 170. 
a redução do seu âmbito de proteção. Ressalta-se ainda que o sistema de reserva constitucional de bens compreende as relações de prevalência ou preferência entre valores constitucionais a serem observadas pelos poderes constituídos (Poder Legislativo, Poder Executivo e Poder Judiciário).

Analisando especificamente o texto constitucional brasileiro, a despeito de inexistir uma categorização hierárquica formal, evidencia-se que o legislador constituinte optou por prever uma grande quantidade de reservas, ora por meio de limites definidos no próprio texto constitucional, ora remetendo ao legislador infraconstitucional a tarefa de conformar o seu conteúdo. Nesse último caso, cabe ao legislador, a partir das indicações previamente estabelecidas pelo texto constitucional ${ }^{26}$, delimitar o âmbito de proteção do direito fundamental ou, por vezes, remeter ao Poder Executivo a responsabilidade por essa ponderação ${ }^{27}$. Entretanto, a tarefa de interpretação da legislação infraconstitucional se mostra particularmente complexa, na medida em que esta tanto pode definir o conteúdo de direito fundamental, como ocasionar uma afetação desvantajosa ${ }^{28}$.

Embora as reservas constitucionais de bens sejam reconhecidas pelas principais teorias dos direitos fundamentais (interna ${ }^{29}$, externa ${ }^{30}$ e dos princípios ${ }^{31}$ ), e por quem adota modelos de interpretação mistos ${ }^{32}$, existem diferenças substanciais quanto ao peso conferido às mesmas. Nesse sentido, concorda-se com o posicionamento de Gomes Canotilho quando critica o peso excessivo atribuído às circunstâncias do caso concreto em face da ponderação realizada pelo legislador constituinte ${ }^{33}$. Entretanto, deve-se advertir que a análise do conjunto de valores constitucionais se resume a consequências jurídicas mecânicas e esquemáticas ${ }^{34}$, pois qualquer ponderação material deve necessariamente avaliar as circunstâncias fáticas.

\footnotetext{
${ }^{26}$ Trata-se, portanto, de um poder vinculado, sob pena de ser declarada a inconstitucionalidade do ato. Cf. Os Direitos Fundamentais na Constituição Portuguesa de 1976, p. 224-225.

${ }^{27}$ Cf. NOVAIS, J. R. As Restrições aos Direitos Fundamentais não expressamente autorizadas pela Constituição, p. 584.

${ }^{28}$ Cf. NOVAIS, J. R. As Restrições aos Direitos Fundamentais não expressamente autorizadas pela Constituição, p. 422-423; e CANOTILHO, J. J. G. Estudos sobre Direitos Fundamentais, p. 208.

${ }^{29}$ Cf. HÄBERLE, P. La Garantia del Contenido Esencial de los Derechos Fundamentales, p. 38.

${ }^{30}$ Cf. NOVAIS, J. R. As Restrições aos Direitos Fundamentais não expressamente autorizadas pela Constituição, p. 559.

${ }^{31}$ Cf. ALEXY, R. Teoria dos Direitos Fundamentais, p. 292.

32 Cf. CANOTILHO, J. J. G. Direito Constitucional e Teoria da Constituição, p. 1271-1273; e NOVAIS, J. R. As Restrições aos Direitos Fundamentais não expressamente autorizadas pela Constituição, p. 598-599. Anota-se que, não obstante Reis Novais aderir a teoria dos princípios, o autor lusitano aceita a teoria dos limites imanentes enquanto reserva geral de ponderação, notadamente porque necessita justificar as restrições aos direitos fundamentais não expressamente previstos pela Constituição. Diferentemente, entendendo que Reis Novais se aproxima do modelo da teoria externa, ver SILVA, V. A. Direitos Fundamentais - Conteúdo Essencial, Restrições e Eficácia, p. 143.

${ }^{33}$ Cf. CANOTILHO, J. J. G. Direito Constitucional e Teoria da Constituição, p. 1272-1273.

${ }^{34}$ Cf. NOVAIS, J. R. As Restrições aos Direitos Fundamentais não expressamente autorizadas pela Constituição, p. 706.
} 
Aliás, o fato das colisões geralmente abrangerem apenas dimensões parcelares e pontuais da esfera da vida ${ }^{35}$ - o que não ocorre no caso de descaracterização do próprio direito fundamental ${ }^{36}$ - reforça a conclusão quanto à inconsistência em aplicar as relações de preferência de modo automático.

Ademais, ainda que uma verificação completa do âmbito de proteção dos direitos fundamentais dependa das diversas situações em concreto, privilegiar de maneira sistemática a ponderação com base em circunstâncias fáticas pode ocasionar um processo de nivelamento entre os valores constitucionais, ou mesmo favorecer a tomada de decisões fortemente influenciadas pela ideologia do seu intérprete.

Se, como afirma Virgílio Afonso da Silva, não é possível buscar uma racionalidade que exclua por completo qualquer subjetividade na interpretação e na aplicação do direito ${ }^{37}$, defende-se que o esforço teórico em delimitar de forma abstrata o conteúdo constitucionalmente protegido tem o mérito de tornar mais previsível e fundamentada a compreensão sobre os direitos fundamentais ${ }^{38}$, além de reconhecer a importância das ponderações realizadas pelo legislador constituinte. Ressalta-se que a relevância em proceder à referida delimitação não se resume à esfera judicial, mas direciona-se igualmente às numerosas ponderações efetuadas pela Administração Pública e pelo legislador infraconstitucional, podendo contribuir para a redução dos conflitos.

É necessário esclarecer que a delimitação abstrata do âmbito de proteção acima assinalado não significa conferir uma posição jurídica definitiva ou um âmbito de garantia efetivo, conforme estabelecido pela teoria interna ${ }^{39}$, pois caberá ainda sopesar as circunstâncias fáticas ${ }^{40}$. Por outro lado, entende-se que reduzir a tarefa de harmonização ao princípio da proporcionalidade como defendido pela teoria dos princípios - é, em determinadas situações, insuficiente para evitar o sacrifício de um dos bens em colisão.

\footnotetext{
${ }^{35}$ Cf. As Restrições aos Direitos Fundamentais não expressamente autorizadas pela Constituição, p. 389. Esclarece-se que as dimensões parcelares se referem a um conflito concreto, e não do direito fundamental como um todo. Cf. Ibid., p. 700.

${ }^{36}$ Nesse caso, resta violado a garantia do núcleo essencial enquanto instituto. Assinala-se que essa descaracterização afeta concomitantemente o direito fundamental em suas dimensões objetiva e subjetiva, o que reforça a necessidade de proteção de ambas. Cf. CANOTILHO, J. J. G. Direito Constitucional e Teoria da Constituição, p. 459.

${ }^{37}$ Cf. SILVA, V. A. Direitos Fundamentais - Conteúdo Essencial, Restrições e Eficácia, p. 146-147.

${ }^{38}$ Acerca desse problema, ver a crítica apresentada por Virgílio Afonso da Silva ao STF, afirmando que este não explicita o caminho que o leva da constatação à conclusão. Cf. SILVA, V. A. Direitos Fundamentais - Conteúdo Essencial, Restrições e Eficácia, p. 105.

${ }^{39}$ Cf. CANOTILHO, J. J. G. Estudos sobre Direitos Fundamentais, p. 201.

${ }^{40}$ Conforme afirma Prieto Sanchís, "(...) o peso definitivo não pode conceber-se como uma simples tradução desse hipotético peso abstrato, pois para a fixação daquele é preciso atender igualmente às concretas valorações indicadas, é dizer, grau de satisfação e de sacrifício de cada um deles". Cf. PRIETO SANCHÍS, L. Justicia Constitucional y Derechos Fundamentales, p. 202. Ver também o conceito de circularidade em NOVAIS, J. R. As Restrições aos Direitos Fundamentais não expressamente autorizadas pela Constituição, p. 689.
} 
Portanto, propõe-se que a busca pela concordância prática deva compreender algumas etapas: a delimitação do âmbito de proteção, as relações de prevalência entre os valores conflitantes ${ }^{41}$ e a verificação da garantia do conteúdo essencial e do princípio da proporcionalidade. Apenas se comprovada a impossibilidade de harmonização é que se admite a adoção do método da ponderação de bens no caso concreto, mesmo existindo relações de preferência prima facie ${ }^{42}$.

\section{ADVERTÊNCIAS METODOLÓGICAS FINAIS}

Observa-se que a metodologia acima apresentada não obedece rigorosamente a nenhuma das principais teorias dos direitos fundamentais. Isso porque, a despeito de admitir a existência de uma reserva geral imanente de ponderação, parte-se de um conceito amplo de suporte fático, de modo a não excluir à partida determinados atos do âmbito de proteção constitucional $^{43}$. Por outro lado, ainda que privilegiado o princípio da concordância prática (harmonização), admite-se, em último caso, a adoção do método da ponderação de bens. Não se entende haver nessa mescla de teorias uma irracionalidade em $\mathrm{si}^{44}$, pois avalia-se ser mais relevante apontar um caminho que propicie a efetividade aos direitos fundamentais.

Ademais, considera-se que o percurso acima trilhado permite identificar aquilo que Juan Moreso ${ }^{45}$ denomina de "propriedades relevantes" e que serviria de referência para futuras colisões, formando uma espécie de sistema de relações abstratas de preferência. Ressalta-se que essa construção não depende exclusivamente da análise de sucessivos precedentes judiciais ${ }^{46}$, sendo igualmente relevante que a mesma seja elaborada a partir da delimitação do âmbito de proteção dos direitos fundamentais. Nesse caso,

${ }^{41}$ Cabe esclarecer que a busca pela harmonização dos bens constitucionais em conflito não necessita pressupor a ideia de que os direitos fundamentais são ordenados em absoluta condição de igualdade, sob pena de tornar iníquo o sistema constitucional de reservas. Portanto, entende-se que a objeção de Konrad Hesse acerca de uma ponderação abstrata de valores se restringe à impossibilidade de sacrificar bens jurídicos constitucionalmente protegidos. Cf. HESSE, K. Temas Fundamentais do Direito Constitucional, p. 113.

42 Registra-se que, de maneira contrária ao que se defende neste trabalho, o método da ponderação de bens exclui a possibilidade de existir relações de preferência prima facie, admitindo-se apenas as relações de precedência concreta. Cf. CANOTILHO, J. J. G. Direito Constitucional e Teoria da Constituição, p. 1240; e ALEXY, R. Teoria dos Direitos Fundamentais, p. 97. Veja-se que Reis Novais, de modo contraditório, afirma que relações de preferência condicionadas decorrem da Constituição, embora em seguida tenha assinalado que, na verdade, dependem da análise das situações concretas. Cf. NOVAIS, J. R. As Restrições aos Direitos Fundamentais não expressamente autorizadas pela Constituição, p. 692.

${ }^{43}$ A garantia de maior efetividade aos direitos fundamentais a partir desse modelo é bastante clara se analisado o exemplo referido em SILVA, V. A. Direitos Fundamentais - Conteúdo Essencial, Restrições e Eficácia, p. 154-155.

${ }^{44}$ Acerca dessa combinação de elementos de várias teorias, ver NOVAIS, J. R. As Restrições aos Direitos Fundamentais não expressamente autorizadas pela Constituição, p. 561-562.

${ }^{45}$ Cf. MORESO, J. J. Conflitos entre Princípios Constitucionais, p. 121; e PRIETO SANCHÍS, L. Justicia Constitucional y Derechos Fundamentales, p. 207-208.

${ }^{46}$ Como é apontado em BOROWSKI, M. La Restricción de los Derechos Fundamentales, p. 47. 
é possível antecipar os eventuais conflitos entre os direitos fundamentais ${ }^{47}$ não apenas a partir dos dispositivos constitucionais, mas igualmente considerando as ponderações realizadas pelo legislador infraconstitucional.

\section{REFERÊNCIAS BIBLIOGRÁFICAS}

ALEXY, Robert. Teoria dos Direitos Fundamentais. São Paulo: Malheiros, 2008.

ANDRADE, José Carlos Vieira de. Os Direitos Fundamentais na Constituição Portuguesa de 1976. 3. ed., Coimbra: Almedina, 2007.

BARCELLOS, Ana Paula de. Ponderação, Racionalidade e Atividade Jurisdicional. Rio de Janeiro: Renovar, 2005.

BOROWSKI, Martin. La Restricción de los Derechos Fundamentales. Revista Española de Derecho Constitucional, n 59, p. 29-56, mayo-agosto 2000.

CANOTILHO, José Joaquim Gomes. Constituição Dirigente e Vinculação do Legislador. Coimbra: Coimbra, 1982.

CANOTILHO, José Joaquim Gomes. Direito Constitucional e Teoria da Constituição. 7. ed., Coimbra: Almedina, 2003.

CANOTILHO, José Joaquim Gomes. Estudos sobre Direitos Fundamentais. São Paulo: RT, 2008.

COUTINHO, Jacinto Nelson de Miranda. Canotilho e a Constituição Dirigente. Rio de Janeiro: Renovar, 2003.

FERNANDEZ SEGADO, Francisco. Estudio Preliminar. Peter Häberle: la giganteca construcción constitucional de um humanista europeo. In: HÄBERLE, P. La Garantia del Contenido Esencial de los Derechos Fundamentales. Madrid: Dykinson, 2003, p. XVII-LXI.

GAVARA DE CARA, Juan Carlos. Derechos Fundamentales y Desarrollo Legislativo: La Garantia del Contenido Esencial de los Derechos Fundamentales en la Ley Fundamental de Bonn. Madrid: Centro de Estudios Constitucionales, 1994.

GIANNINI, Massimo Severo. Basi Costituzionali della Proprietà Privata. In: Scritti. vol. 6, 1970-1976. Giuffrè, 2005, p. 187-245.

GROSSI, Pierfrancesco. Introduzione ad uno Studio sui Diritti Inviolabili nella Costituzione Italiana. Padova: CEDAM, 1972.

HÄBERLE, Peter. La Garantia del Contenido Esencial de los Derechos Fundamentales. Madrid: Dykinson, 2003.

HESSE, Konrad. Temas Fundamentais do Direito Constitucional. São Paulo: Saraiva, 2009.

LARENZ, Karl. Metodologia da Ciência do Direito. 4. ed., Lisboa: Fundação Calouste Gulbenkian, 2005.

MEDINA GUERRERO, Manuel. La Vinculacion Negativa del Legislador a los Derechos Fundamentales. Madrid: MacGraw-Hill, 1996.

\footnotetext{
47 No mesmo sentido, ver BARCELlOS, A. P. Ponderação, Racionalidade e Atividade Jurisdicional, p. 146-155. Para uma postura crítica acerca dos critérios de essencialidade dos direitos fundamentais, ver GROSSI, P. Introduzione ad uno Studio sui Diritti Inviolabili nella Costituzione Italiana, p. 158.
} 
MORESO, José Juan. Conflitos entre Princípios Constitucionais. In: CARBONELL, M. (Org.). Neoconstitucionalismo (s). Madrid: Editorial Trotta, 2003, p. 99-121.

NOVAIS, Jorge Reis. As Restrições aos Direitos Fundamentais não expressamente autorizadas pela Constituição. Coimbra: Coimbra Editora, 2003.

PRIETO SANCHÍS, Luis. Justicia Constitucional y Derechos Fundamentales. Madrid: Trotta, 2003.

SARLET, Ingo Wolfang. A Eficácia dos Direitos Fundamentais. 9. ed., Porto Alegre: Livraria do Advogado, 2007.

SILVA, Virgílio Afonso da. Direitos Fundamentais - Conteúdo Essencial, Restrições e Eficácia. São Paulo: Malheiros, 2009.

TEPEDINO, Gustavo. Normas Constitucionais e Relações de Direito Civil na Experiência Brasileira. Boletim da Faculdade de Direito. Coimbra. Separata 1999/2000, p. 323-345. 